\title{
Fatigue Response of Cold-Rolled Type-304 Stainless Steel Foil
}

\author{
Thomas P. Kieffer*, James I. Hardy \\ Micro-Measurements, Vishay Precision Group, Wendell, USA \\ Email: ^tom.kieffer@VPGsensors.com
}

How to cite this paper: Kieffer, T.P. and Hardy, J.I. (2021) Fatigue Response of Cold-Rolled Type-304 Stainless Steel Foil. Journal of Minerals and Materials Characterization and Engineering, 9, 90-99. https://doi.org/10.4236/jmmce.2021.91007

Received: December 16, 2020

Accepted: January 26, 2021

Published: January 29, 2021

Copyright (อ 2021 by author(s) and Scientific Research Publishing Inc. This work is licensed under the Creative Commons Attribution International License (CC BY 4.0).

http://creativecommons.org/licenses/by/4.0/ (c) (i) Open Access

\begin{abstract}
This study presents the fatigue response of 304 stainless steel foil, cold-rolled to a thickness of $3.2 \mu \mathrm{m}$ with 87 percent cold work at orientations of 0,45 , and 90 degrees to the direction of rolling. Fatigue specimens were fabricated by laminating a supportive layer of $20-\mu \mathrm{m}$ polyimide film to one side of the foil and patterning 242 crack initiation features by photolithographic process. Progression of fatigue damage was determined through electrical resistance measurement. The fatigue response was demonstrated to be largely affected by anisotropy existing between the rolling direction and the off-axis orientations. Fatigue cracks that traveled in a direction parallel to the elongated grains (cyclic loads applied at 90-degree orientation to foil rolling direction) had the most fatigue response (undesirable characteristic). The construction of the specimens with thin foil supported by a film backing contributed to high fatigue threshold.
\end{abstract}

\section{Keywords}

Fatigue, Cold-Rolled Foil, Type-304 Stainless Steel, Resistive-Sensing, Anisotropy

\section{Introduction}

Fatigue test results can be sensitive to a number of factors including test method, surface finish, notch sensitivity, etc. One conservative design rule suggests 304 stainless steel be assigned an endurance limit of about $240 \mathrm{MPa}$ or about 50 percent of the ultimate tensile strength [1]. The cold rolling process can increase the tensile strength of the material and consequently the fatigue strength has been reported to be considerably greater than the design rule. One study reported 300 $\mu \mathrm{m}$ thick cold-rolled strip had an endurance limit of about $600 \mathrm{MPa}$ [2]. Another study reported $0.76 \mathrm{~mm}$ thick cold-rolled strip with 50 percent cold work had an 
endurance limit of about $500 \mathrm{MPa}$ [3].

Other factors should be considered when assigning a design limit. For example, the cold rolling process can impart anisotropy into the material causing the mechanical properties to vary depending upon the orientation of the specimen to the rolling direction. The highest strength is generally in the direction of rolling. Regarding fatigue strength, anisotropy can be detrimental, particularly if tensile stresses are applied in a direction that is nearly perpendicular to the long dimension of elongated grains [4]. For the case of cold-rolled foil, this unfavorable stress application direction would be at an angle of 90 degrees to the rolling direction (the transverse direction).

Scale (size) is another consideration and has been shown to have an effect on fatigue strength. In one study micrometer-scale fatigue specimens $25 \mu \mathrm{m}$ thick made of 304 stainless steel demonstrated higher fatigue strength than bulk properties. The smaller specimens failed at about 20,000 cycles for stresses of $\pm 400 \mathrm{MPa}$ and had an endurance limit of about $250 \mathrm{MPa}$ for fully-reversed bending stresses $(R=-1)$. Whereas, the bulk material was reported to fail at about 20,000 cycles for stresses of $\pm 210 \mathrm{MPa}$ with an endurance limit of about $150 \mathrm{MPa}$ [5]. Other studies using a variety of specimen shapes and loading methods (cantilever, rotary bending, and tension) with section thicknesses of 1 to $30 \mathrm{~mm}$ reported comparable endurance limits of 100 to $250 \mathrm{MPa}$ [6] [7] [8] [9] [10].

Specimens made with cold-rolled foil present challenges such as how to hold the specimen and how to apply the cyclic load during the fatigue test. In all of the studies mentioned above the fatigue specimens were generally thick enough to be held (gripped) on the ends. One notable experimental method was the study that used micrometer-scale cantilever fatigue specimens $25 \mu \mathrm{m}$ in thickness [5]. The specimens started in sheet form and the sides of individual specimens were machined away everywhere except for the fixed ends. This enabled reaction forces to be developed to the applied forces. In addition to gripping the fatigue specimen made of foil, another consideration is the ability of the specimen to withstand an in-plane compressive load without buckling or an out-of-plane bending load without folding. Our solution was to laminate a thin polyimide film to the foil to provide support. This is described in detail in the Experimental Methods section.

Finally, our expectation was the cold-rolled 304 stainless steel foil would exhibit a significant amount of anisotropy between the fatigue response of the foil in the direction of rolling and transverse to the direction of rolling. We expected the former to have a better fatigue response (more cycles to failure) than the latter. We also expected the foil in the direction of rolling would demonstrate similar and possibly greater fatigue strength than the results reported in the studies on cold-rolled strip [2] [3] for several reasons. First, there was the issue of scale. With the cold-rolled foil being thinner than the cold-rolled strip, scale considerations would suggest greater fatigue strength [5]. Second, there was the issue of higher tensile strength. The cold-rolled foil would have more cold work than the 
cold-rolled strip and consequently higher tensile strength. Finally, the polyimide film laminated to one side of the foil would help to provide more uniform loading and reduce extraneous forces.

\section{Experimental Methods}

The following sections describe the foil material, the fatigue specimens, and other materials used in this study.

\subsection{Foil Material}

The material used for this study was Grade 304 stainless steel per ASTM specification A240. The chemical composition by weight percent is provided in Table 1.

The minimum mechanical properties were yield strength (205 MPa), tensile strength (515 MPa), elongation (40 percent), and hardness (92 Rockwell B). The material was sourced in the form of a sheet $127 \mu$ m thick $\times 30.5 \mathrm{~cm}$ wide $\times 7.6 \mathrm{~m}$ long in cold-rolled and annealed condition. The sheet was subsequently divided (slit) into strips $108 \mathrm{~mm}$ wide and cold rolled to an intermediate thickness of $25.4 \mu \mathrm{m}$. At this thickness, an in-process, bright anneal (hydrogen) was performed at a temperature of $1311 \mathrm{~K}$ for a duration of $96 \mathrm{~s}$. Cold rolling resumed to a final thickness of $3.2 \mu \mathrm{m}$. This corresponded to 87.4 percent cold work from the prior anneal. A post-rolling, final anneal in inert atmosphere was performed at a temperature of $644 \mathrm{~K}$ for a duration of $90 \mathrm{~min}$.

A view of the grain structure of the finished foil is provided in Figure 1. As expected with heavily cold-worked foil, the grains were elongated in appearance with an aspect ratio of approximately 4:1 in the direction of foil rolling. The grain size was estimated as ASTM No. 8 .

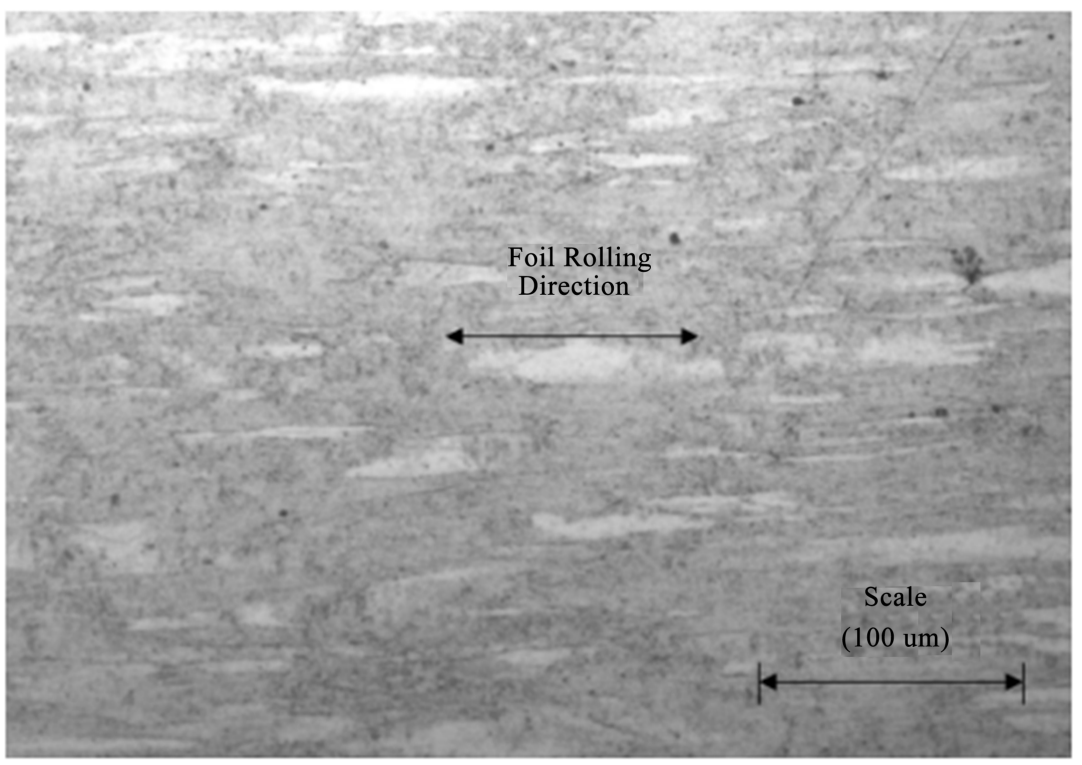

Figure 1. Representative grain structure of $3.2 \mu \mathrm{m}$ thick, 87 percent cold-worked, 304 stainless steel foil (modified Kalling's reagent at $200 \times$ magnification). 
Table 1. Chemical composition (Weight percent).

\begin{tabular}{cccccccc}
\hline $\mathrm{Cr}$ & $\mathrm{Ni}$ & $\mathrm{Mn}$ & $\mathrm{N}$ & $\mathrm{S}$ & $\mathrm{C}$ & $\mathrm{Si}$ & $\mathrm{P}$ \\
\hline $18-20$ & $8-10.5$ & 2 & 0.1 & 0.03 & 0.08 & 0.75 & 0.045 \\
\hline
\end{tabular}

\subsection{Fatigue Specimens}

Using a photolithographic process, multiple fatigue specimens were produced simultaneously from pieces of the 3.2- $\mu \mathrm{m}$ thick 304 stainless steel foil. A supportive backing made of $20-\mu \mathrm{m}$ thick polyimide film was laminated to the foil with epoxy adhesive. The pattern (image) of the fatigue specimens was formed by application of a photoresist liquid to the surface of the 304 stainless steel foil, light exposure through an optical mask, and development with a solvent. Metal removal was by wet process with metal-chloride spray. The overall thickness of the fatigue specimens including supportive backing, layer of laminating epoxy, and 304 stainless foil was about $26 \mu \mathrm{m}$.

Fatigue specimens were designed for cyclic load application over their entire surface area by transmission of the surface strain occurring on an actuating member through the $20-\mu \mathrm{m}$ thick polyimide supportive backing and into the 304 stainless steel foil [11]. A quantity of 242 discrete crack initiation features was patterned into each fatigue specimen in the form of pairs of active-passive traces placed in series with each other as shown in Figure 2. The active traces containing crack initiation features were modeled after the extended compact tension specimen developed at NASA Langley Research Center [12].

Images of fatigue specimens on the photomask were oriented at 0,45 , and 90 degrees to the direction of foil rolling. The crack initiation features and fatigue cracks propagating therefrom were thereby oriented at 0,45 , and 90 degrees to the direction of foil rolling. The sensing area of the fatigue specimen was 34.3 $\mathrm{mm}^{2}$, having a length of $6.6 \mathrm{~mm}$ and a width of $5.2 \mathrm{~mm}$. The widths of the active and passive traces were $75 \mu \mathrm{m}$ and $25 \mu \mathrm{m}$, respectively. The depth of the crack initiation feature was $25 \mu \mathrm{m}$ leaving a $50-\mu \mathrm{m}$ long path for the fatigue crack to propagate across the active trace.

Progression of fatigue damage was determined through resistive sensing. The electrical resistance of the patterned 304 stainless steel foil was nominally 700 ohms prior to crack formation. As cracks formed at the tips of the crack initiation features and propagated across the width of the active traces, the electrical resistance of the active-passive trace pairs increased. The final (terminal) resistance of each active-passive trace pair approached the resistance of the passive trace when the fatigue crack propagated completely across to the opposite edge of the active trace. The electrical resistance of the entire fatigue specimen represented the sum of the active-passive trace pairs. The higher the electrical resistance of the fatigue specimen, the greater the number and/or the length of fatigue cracks. The large number of crack initiation features (242) was intended to self-normalize the fatigue response of the 304 stainless steel foil. Undoubtedly, there would be a distribution of crack behaviors ranging from crack initiation to 


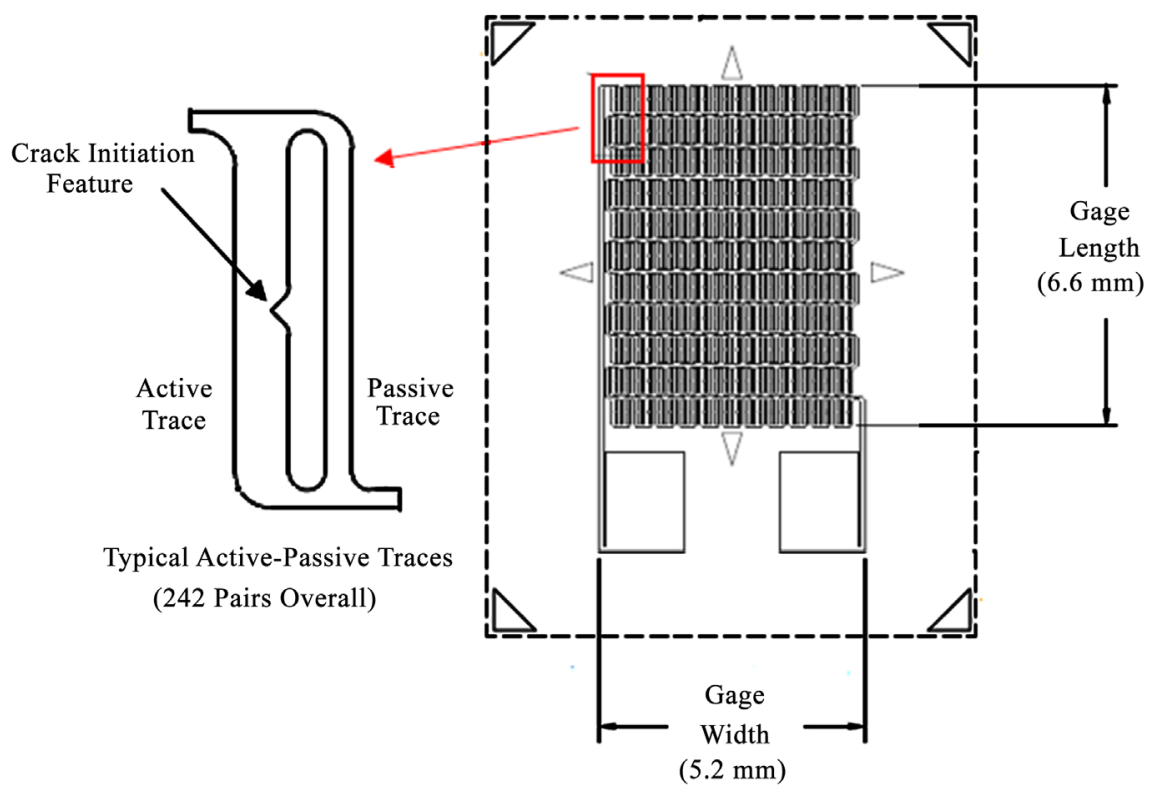

Figure 2. Fatigue specimen (304 stainless steel foil) including 242 pairs of active-passive traces and crack initiation features.

crack propagation. The total electrical resistance of the summed active-passive pairs evened out these variations.

\subsection{Other Materials}

Fatigue specimens were bonded to cantilever beams with cyanoacrylate adhesive and oscillating loads were applied using a solenoid coil as shown in Figure 3. The surface strain on the cantilever beam was transmitted upwards through the cyanoacrylate bonding adhesive and through the polyimide film base layer of the fatigue specimen and finally to the $3.2 \mu \mathrm{m}$ thick 304 stainless steel foil. Four fatigue specimens were bonded to the top surface of the beams, arranged as two pairs of specimens side-by-side, with a reference strain gage in between each pair. There were five cantilever beams for each orientation to the direction of foil rolling $(0,45$, and 90 degrees) for a total of 60 fatigue specimens ( 20 for each foil orientation). The applied strains were fully-reversed $(\mathrm{R}=-1)$ and constant for each beam ranging from about $\pm 1800 \mu \mathrm{E}$ to $\pm 2600 \mu \mathrm{E}$ in steps of $\pm 200 \mu \mathrm{E}$ per beam.

The cantilever beams were made of $3.6 \mathrm{~mm}$ thick fiberglass with a flexural modulus of $38.6 \mathrm{GPa}$. The sides of the cantilever beams were tapered to reduce the strain gradient along the length of the beam to a difference of about $300 \mu \mathrm{E}$ between the near pair of fatigue specimens to the distant pair. Loading was applied to the ends of the cantilever beams through a screw made of steel aligned with the vertical axis of a $30 \mathrm{~W}$ solenoid coil operating between 20 and $28 \mathrm{~V}$ depending upon the strain level desired. The frequency of oscillation was about 95 $\mathrm{Hz}$ and was adjusted with a square wave frequency generator to be near the resonant frequency for the beam. 


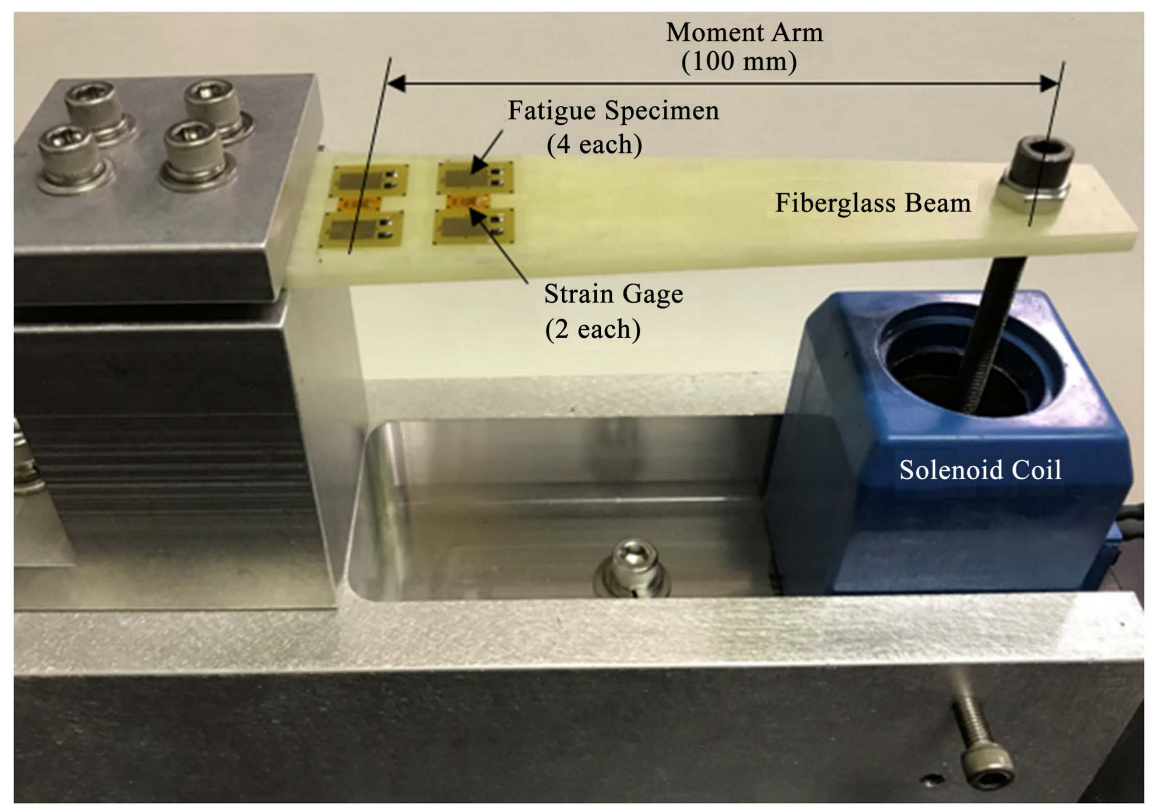

Figure 3. Fatigue specimens (304 stainless steel foil) and reference strain gages bonded to fiberglass beam with cyclic loads applied by solenoid coil.

The resistance of each fatigue specimen was recorded using a Keithley model 2750 multimeter before applying loads and subsequently while the beams were stopped after each of eight time intervals of $1,2,4$, and 8 min duration. The total elapsed time was $120 \mathrm{~min}$ and the total number of load cycles was about 700,000 depending upon the frequency of oscillation of each beam. To facilitate comparison between the test conditions (foil orientation and applied strain level), fractional resistance was calculated by subtracting the initial resistance reading from each subsequent resistance reading and dividing the difference by the initial resistance reading.

\section{Results}

Plots of fractional resistance $(\Delta \mathrm{R} / \mathrm{R})$ versus number of applied strain cycles for the three orientations to the direction of foil rolling $(0,45$, and 90 degrees) are provided in Figure 4. For ease of presentation, the data provided were limited to those cases where the terminal fractional resistance achieved at least 5 percent. There were five test cases that met these criteria: all of the orientations for an applied strain level of $\pm 2600 \mu \mathrm{E}$ and the 45 and 90 degree orientations for applied strain levels of \pm 2390 and $\pm 2290 \mu \mathrm{E}$, respectively.

All of the plots had a characteristic shape with three distinct regions: in the first region between 0 and about 50,000 strain cycles, there was negligible change in fractional resistance. This region was followed by a second region of rapidly increasing fractional resistance between about 50,000 and 200,000 strain cycles. Finally, the third region was represented by slower increase in fractional resistance to an asymptote in the range of 200,000 to 400,000 strain cycles.

Fatigue specimens with 90-degree orientation to the direction of foil rolling 
Fractional Resistance, $\Delta \mathrm{R} / \mathrm{R}$ (percent)

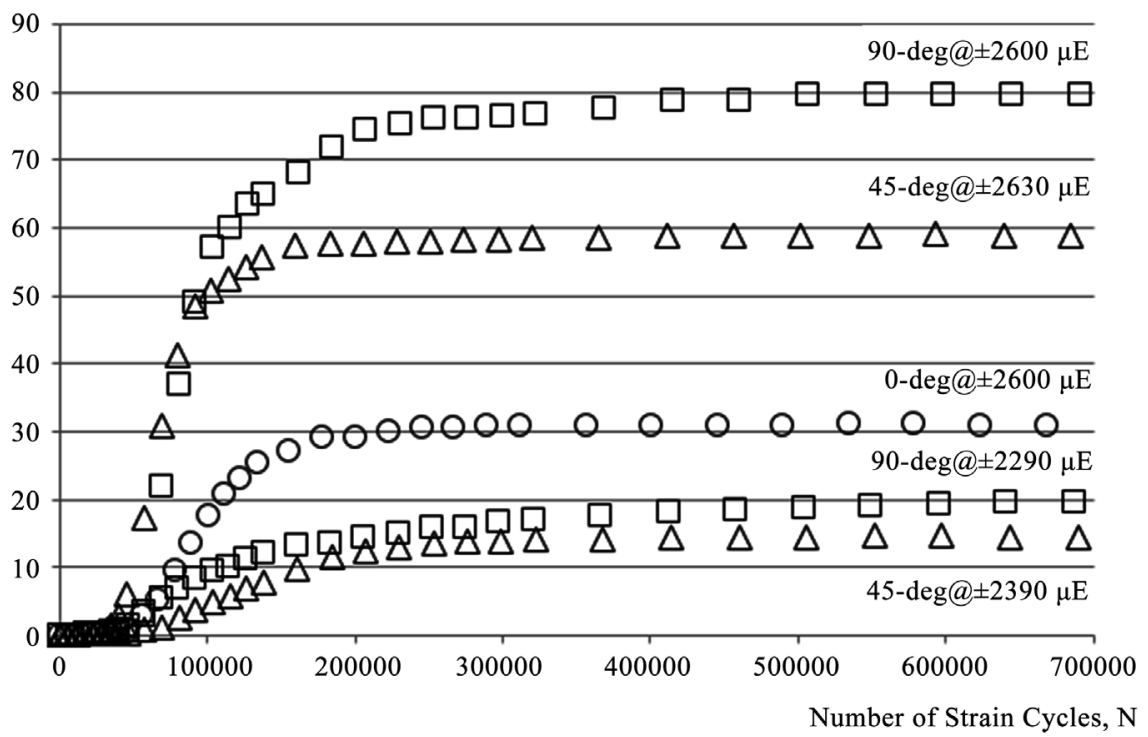

Figure 4. Fatigue testing results for specimens (304 stainless steel foil) oriented at 0, 45, and 90 degrees to the direction of rolling.

had the highest rate of fractional resistance increase in the second region and the highest magnitude fractional resistance (asymptote) in the third region. For a strain level of $\pm 2600 \mu \mathrm{E}$, the 90 -degree orientation had a terminal fractional resistance of about 80 percent. The next highest fractional resistance in the second and third regions was for the 45-degree orientation to the direction of foil rolling. For a strain level of $\pm 2630 \mu \mathrm{E}$, the 45 -degree orientation had a terminal fractional resistance of about 58 percent. Finally, the third highest fractional resistance response was for the 0 -degree orientation, which demonstrated a terminal fractional resistance of about 31 percent for a strain level of $\pm 2600 \mu \mathrm{E}$.

A photograph of the patterned 304 stainless steel foil oriented at 90 degrees to the direction of foil rolling after 690,000 load cycles of $\pm 2600 \mu \mathrm{E}$ is provided in Figure 5. Two pairs of active-passive traces are shown. Fatigue cracks are visible and have propagated from the crack initiation features completely across the width of the active traces, which is a distance of $50 \mu \mathrm{m}$. The grain structure is also visible and the cracks have travelled in directions that are parallel to the elongated grains (the direction of rolling).

\section{Discussion}

The characteristic shape of the fractional resistance plots with three regions of response corresponded to the summation of crack initiation and propagation behavior in the 242 active-passive trace pairs. In the first region, crack initiation and propagation resulted in negligible increase in fractional resistance. This is not to say that cracks had not formed, rather this might have been because few of the active traces had been severed. Whereas, in the second region of rapid increase in fractional resistance, this was probably the result of an increasing 


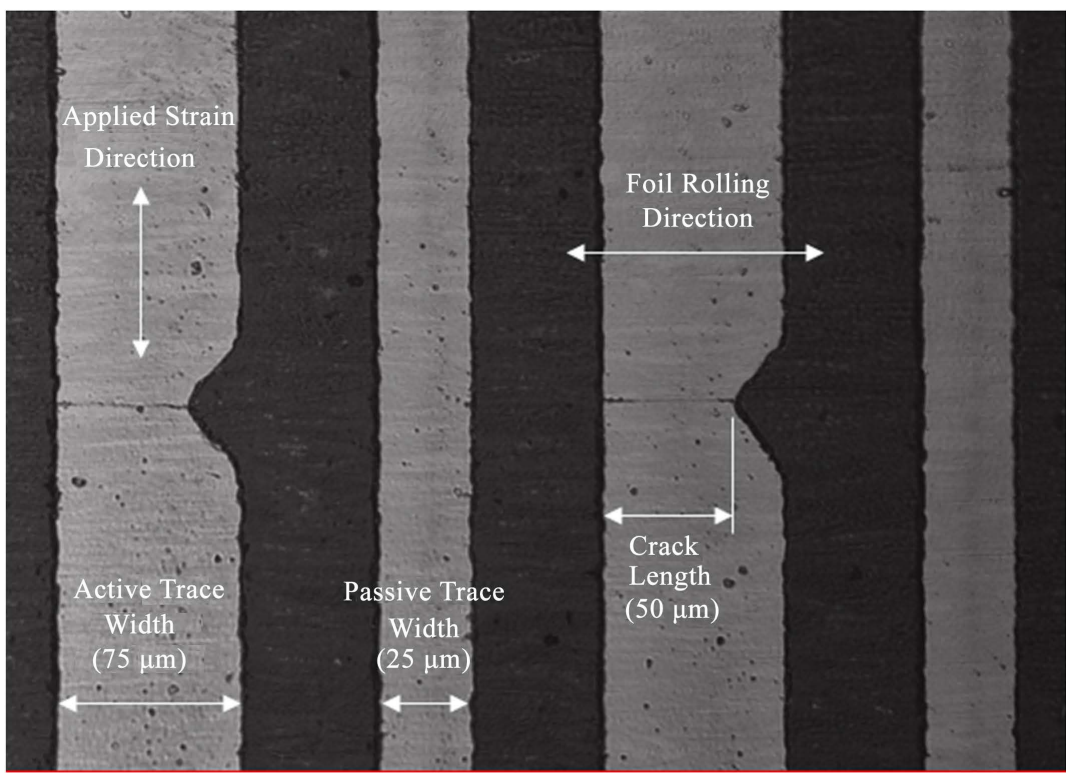

Figure 5. Two pairs of active-passive traces after 690,000 load application cycles of \pm 2600 $\mu \mathrm{E}$ at 90 -degree orientation to foil rolling direction (200× magnification).

number of cracks having traveled completely across the width of the active traces. Finally, in the third region the rate of increase in fractional resistance was reduced as an asymptote was approached, which probably signified an end to fatigue cracks severing the active traces.

It was expected there would be some difference in fatigue response between the three orientations to the direction of foil rolling $(0,45$, and 90 degrees) because of the amount of cold work in the rolled foil ( 87 percent). The magnitude of the difference was not expected with the off-axis orientations (45 and 90 degree) demonstrating significantly higher responses compared to the direction of rolling ( 0 degree). For the strain level of $\pm 2600 \mu \mathrm{E}$, the terminal fractional resistances for the 90 and 45-degree orientations were about 260 and 190 percent of the 0 -degree orientation, respectively.

Finally, the data for test cases not meeting a criterion of 5 percent terminal fractional resistance represented the majority of the test cases. Specifically, this included applied strain levels of $\pm 1800, \pm 2000$, and $\pm 2200 \mu \mathrm{E}$. The applied stresses corresponding to these strain levels were about 340,380, and $420 \mathrm{MPa}$, respectively. All of these stress levels would likely have produced fatigue damage in thicker specimens. Possible explanations for the negligible response of the fatigue specimens used herein could be the diminutive thickness $(3.2 \mu \mathrm{m})$ of the 304 stainless steel foil and, perhaps the interaction with the supportive layer of polyimide film $(20 \mu \mathrm{m})$ under the foil. This is in contrast to conventional fatigue specimens, which are typically held (gripped) at the ends and are unsupported in the area of the notches (crack initiation features).

\section{Conclusion}

The fatigue response of cold-rolled 304 stainless steel foil was demonstrated to 
be largely affected by anisotropy existing between the rolling direction ( 0 degree) and off-axis orientations (45 and 90 degrees). Fatigue cracks which traveled in a direction parallel to the elongated grains (cyclic loads applied at 90-degree orientation to foil rolling direction) of the heavily cold-worked foil (87 percent) had the most fatigue response (undesirable characteristic). Whereas, fatigue cracks which traveled in a direction perpendicular to the elongated grains (cyclic loads applied in rolling direction) had the least fatigue response. Furthermore, the construction of the specimens with thin foil $(3.2 \mu \mathrm{m})$ supported by a $20-\mu \mathrm{m}$ thick polyimide film backing contributed to a high fatigue threshold.

\section{Conflicts of Interest}

The authors declare no conflicts of interest regarding the publication of this paper.

\section{References}

[1] British Stainless Steel Association (2018) Fatigue Properties and Endurance Limits of Stainless Steels. Pegasus House, Sheffield.

[2] Al-Bakri, A.A., Sajuri, Z., Abdulrazzaq, M., Ariffin, A.K. and Fafmin, M.S. (2017) Fatigue Properties of Strained Very Thin 304 Stainless Steel Sheets. International Journal of Automotive and Mechanical Engineering, 14, 4171-4182. https://doi.org/10.15282/ijame.14.2.2017.5.0334

[3] Wright, R.N. (1976) The High Cycle Fatigue Strength of Commercial Stainless Steel Strip. Material Science and Engineering, 22, 223-230.

https://doi.org/10.1016/0025-5416(76)90158-0

[4] Boardman, B. (1990) Fatigue Resistance of Steels. In: ASM Handbook Program, Ed., Properties and Selection: Irons, Steels, and High-Performance Alloys, ASM International, Materials Park. https://doi.org/10.31399/asm.hb.v01.a0001038

[5] Zhang, G.P., Takashima, K. and Higo, Y. (2006) Fatigue Strength of Small-Scale Type 304 Stainless Steel Thin Films. Material Science and Engineering, 426, 95-100. https://doi.org/10.1016/j.msea.2006.03.090

[6] Haidyrah, A.S.R. (2015) Characterization of Bending Fatigue Mini-Specimens for Nuclear Materials. Ph.D. Thesis, Missouri University of Science and Technology, Rolla. https://doi.org/10.1007/978-3-319-48127-2 148

[7] Muñoz-Cubillos, J., Coronado, J.J. and Rodríguez, S.A. (2017) Deep Rolling Effect on Fatigue Behavior of Austenitic Stainless Steels. International Journal of Fatigue, 95, 120-131. https://doi.org/10.1016/j.ijfatigue.2016.10.008

[8] Jayaprakash, M., Mustapa, M.S., Mohd, S., Muhammad, W.N.A.W. and Nithya Gnana Poorani, S.C. (2016) Fatigue Behavior of AISI 304 Stainless Steel under Fretting. ARPN Journal of Engineering and Applied Sciences, 11, 7655-7658.

[9] Ray, K.K., Duttab, K., Sivaprasadc, S. and Tarafderc, S. (2016) Fatigue Damage of AISI 304 LN Stainless Steel: Role of Mean Stress. Procedia Engineering, 2, 1805-1813. https://doi.org/10.1016/j.proeng.2010.03.194

[10] Deng, G.J., Tu, S.T., Wang, Q.Q., Zhang, X.C. and Xuan, F.Z. (2014) Small Fatigue Crack Growth Mechanisms of 304 Stainless Steel under Different Stress Levels. International Journal of Fatigue, 64, 14-21.

https://doi.org/10.1016/j.ijfatigue.2014.01.027 
[11] Kieffer, T.P., Hardy, J.I. and Watson, R.B. (2020) Fatigue Life Sensor. US Patent Application No. 16/853,255.

[12] Piascik, R.S. and Newman, J.C. (1996) An Extended Compact Tension Specimen for Fatigue Crack Propagation and Fracture. International Journal of Fracture, 76, 43-48. https://doi.org/10.1007/BF00048293 